\title{
Grid Project Cost Control Research Based on Data Mining
}

\author{
Yan Peng ${ }^{1, *}$, Yang Ding ${ }^{2}$ and Yuanmei $\mathrm{Yu}^{3}$ \\ ${ }^{1}$ Jilin Jilin Northeast Dianli University 132012, China \\ ${ }^{2}$ Liaoning Dalian 116033, China \\ ${ }^{3}$ Jilin Changchun The first hospital of Jilin University 132000, China \\ "Corresponding author
}

\begin{abstract}
As the prevalence of the Internet +and big data, Chinese construction industry, especially, such as grid construction that it is high -investment projects. They are actively reform, strengthen project cost management, to adapt to the new requirements of the times. The paper analyzed and assessed grid project cost from the perspective of data mining, and elaborating it in detail from the whole process of the project cost, putting forward reasonable proposals for cost control.
\end{abstract}

\section{Keywords-data mining; grid project cost; cost control}

\section{INTRODUCTION}

Cost management and control is a management activity that refers to reaching the requirements of project quality and safety, on the costs that generated in the process of implementation of the project, through a series of planning, organization and control in order to achieve the desired costs goal, to achieve the lowest cost and maximum benefits. In recent years, our country advocated strongly the market-oriented reforms on the grid, combining the characteristics of the power grid construction, to build the power grid construction cost data mining model, achieve cost control and project cost variance analysis based on data mining, which can further strengthen the power grid construction management, play better engineering economic and social benefits.

\section{THE IMPORTANCE OF PROJECT COST CONTROL}

\section{A. Project Cost Control Problems Existed}

There is a direct link between the cost control of architectural Engineering and the economic efficiency of construction enterprise, the present stage cost control in china, over budget and so widespread, these phenomena largely affected the construction enterprise management rationalization, specific questions are as follows.

1) Project cost members did not meet the standard of professional skills: For grid companies, the cost sector is a necessary prerequisite for getting on smoothly tender and improving profitability, However, at present, the problem that economic and technical separated on the construction field is widespread, technical staff ignored the project cost; on the other hand, the cost members generally do not understand the technical knowledge about the engineering technology, so the construction cost would be difficult to determine reasonably and controlled effectively.
2) Tendering and bidding is not standardized: Bidding irregularities mainly show the manual operation, deliberately suppressed project cost, which in the cost administration was unable to correctly judge the cost of the project, and pose a serious threat to the engineering quality and safety, increase the difficulty of the work of relevant departments.

3) Enterprise quota is not standardized: Different construction companies, there is a big difference between different building projects and different construction companies. Grid as a special industry, in the construction process, the selected equipment, technology, capital and raw materials have special requirements, these requirements often require large amounts of data as a basis for analysis, but in practice, companies often ignore this, resulting in quota happening deviation, affecting the liquidity of enterprise capital.

4) Subjective waste phenomenon is more serious: We usually unable to determine the fixed standard to limit the late work in the design phase of construction projects, which in the waste phenomenon occurs sometimes. Designers change design, impacting the authenticity of project cost.

\section{B. Significance of Project Cost Control}

Construction project cost control is closely related to the interests of business. After selecting the project, investors begin to carry on a series of investment management activities: assessment decision, bidding design, bidding,contract, organization of construction, completion and acceptance. All expenses paid in investment activities constitute a project cost, so the success of project cost control is directly related to the profitability of the enterprise. Strengthen cost management enables effectively control cost, reduce investment and operating costs, enhance the company's operating capability and competitiveness. The level of cost control will greatly reduce investment and increase revenue, so, construction cost and cost control must be placed in an important strategic position.

Building construction is a job that involves many fields, in the market economy, the construction industry rapidly develop, great changes occurred in the project cost, kind of valuation method is even more numerous and complex. Especially the power grid and other major projects, because of its large amount of investment, its project cost management is more 
important. In the course of the project implementation, reasonable cost control measures and strict cost management are guarantee of quality and efficiency of project ${ }^{[1]}$.

In essence, the perfect construction project cost control efforts are not just make the project investment capital is controlled within a limited range, but also make full use of resources to obtain more economic benefits. In the process of economy from planned to market economy, the construction industry has also been a corresponding reforms. However, the traditional management model lags, many management does not implement radical reforms, which have a certain influence to construction project cost and cost control ${ }^{[2]}$. If construction enterprises want to obtain economic benefits in construction, achieve their own development, they need to take effective measures to solve the existing problems and good construction project cost and cost control efforts.

\section{THE CONTENT OF GRID PROJECT COST CONTROL}

The entire life cycle time grid construction projects is very long, and the contents in the various phases of the project are not the same, similar to other construction projects, the whole life cycle of the power grid construction project also includes a plurality of stages: investment decision-making, design, bidding, construction, completion and acceptance, operation and maintenance and so on. To better achieve grid construction project cost management and achieve maximum benefit, we should control all aspects of the whole process ${ }^{[3-5]}$.

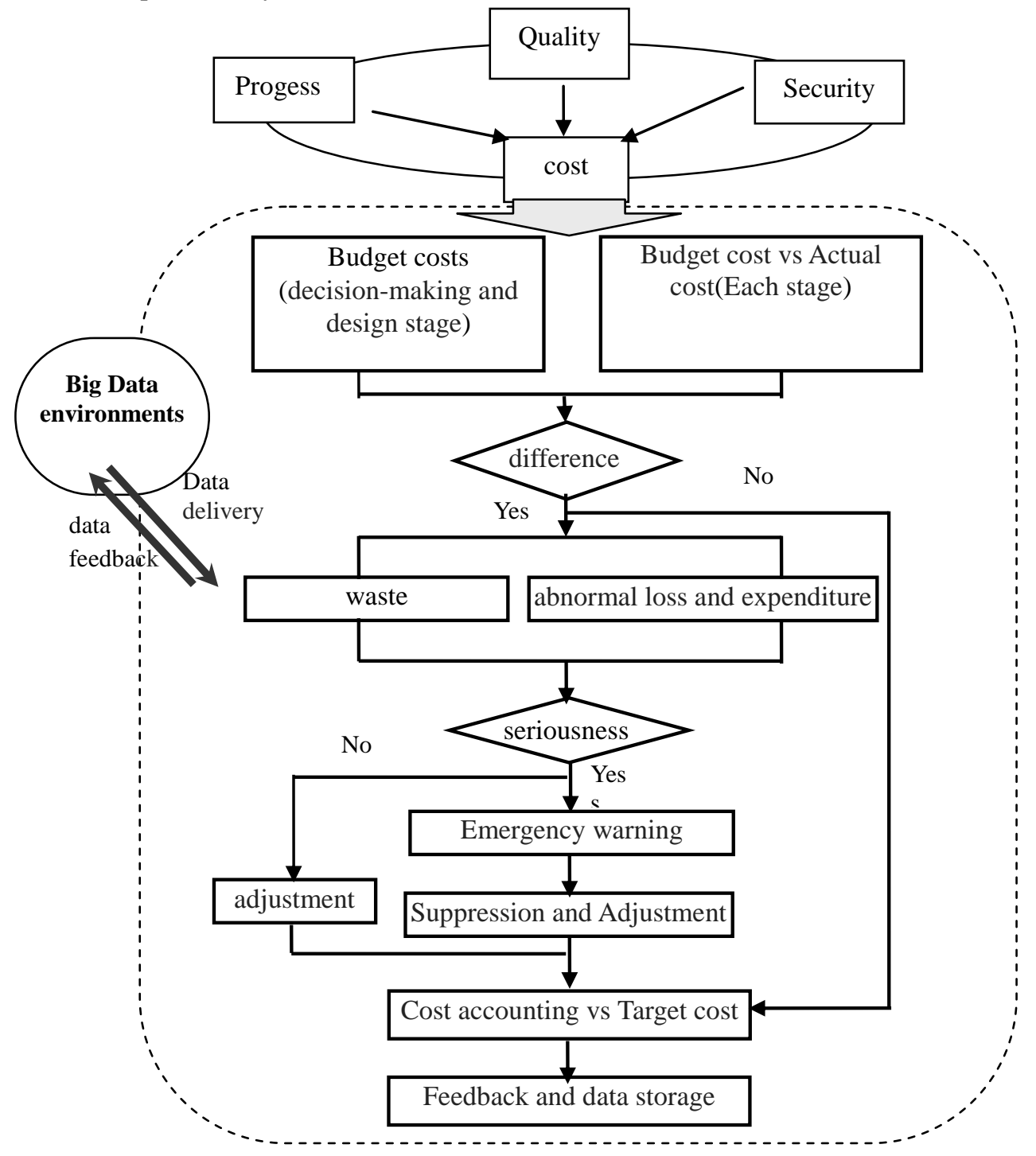

FIGURE I. FLOWCHARTOF CONSTRUCTION COSTS CONTROL UNDER DATE MINING

\section{A. The Cost Control of INVESTMENT Decision-Making Stage}

Exist between the various aspects of a close relationship, and thus the cost of the project cost control must proceed from the initial construction project, namely investment decision-making stage, permeate all aspects ${ }^{[6]}$. Cost control in this phase is the premise cost of each of the other stages, based on the entire project cycle, the cost control need to estimate the funds that needed for the project according to the actual 
situation .When making estimates, there are certain to reserve fund to guard against the risk, with the aim to achieve a minimum cost of total project, a more rational use of human, material and financial resources, finally achieving the maximum investment returns.

\section{B. The Cost Management of the Design Phase}

The design phase is a key of construction project cost control, and playing a connecting role. The proportion of design costs of total costs is only $2 \%-3 \%$, although this percentage is small, but its impact on the project cost up to $75-85 \%$, and even larger proportion, this shows that the merits of the project design will directly affect the total cost, processes, quality and safety, etc., directly determine the inputs of human, material and financial resources. Design stage construction cost control mainly includes two aspects:the design of the tender and the setting of quota ${ }^{[7.8]}$.

\section{The Cost Control of the Bidding Phase}

Bidding is essentially competing under market economy conditions, each one of the various stages of project costs amount can be clearly presented in this stage. The work of bidding phase will directly affect the construction project progress and the project cost, and facilitate for enterprises to select construction enterprises which are short duration, low cost, quality and security.

\section{The Cost Control of the Construction Phase}

Construction phase of the project is the stage that the capital investment is largest, and is an extension and practice of the previous stage. Strengthen the construction cost control, it is to strengthen the management of compliance behavior. At this stage, we are suppose to pay attention to strengthening contract management, improving the supervision mechanism, enhancing the economic and technical means, scientifically selecting the equipment, materials, etc.

\section{E. The Cost Control of the Final Acceptance Stage}

The main work of this stage is to truthfully review be completed engineering review, according to national or local relevant regulations, contracts, budgets and fixed costs, completion data, carefully examine the project payment. Making settlement audited truly reflects the actual cost, to achieve a virtuous circle ${ }^{[8]}$.

\section{Completes Reasonable Proposals of the GRID CONSTRUCTION PROJECT ENGINEERING COST AND COST CONTROL}

\section{A. Improve the Relevant Personnel Cost Control Awareness and Professional Skills}

Only when all the staff of enterprises have awareness of cost control, companies will be able to do a good job cost control cost, reduce the cost of construction of the project cost and improve economic efficiency of enterprises. First of all, enterprises should strengthen the training of all staff and improve the staff's awareness of cost control and professional skills $^{[9]}$. Secondly, the enterprise management personnel need to develop a sound responsibility management system, the cost target specific to each one-way project even specific to each staff. Finally, the establishment of reward and punishment system, as long as it can effectively reduce the cost should be appropriate incentives to encourage the parties to try to reduce the cost of the project.

\section{B. The Use of Information Technology to Strengthen the Construction Cost Management}

With the continuous development of the Internet, big data and other science and technology, cost accounting methods are constantly updated, cost management and control that based on data mining is one of the effective ways. A variety of project management cost data is more dispersed, using the computer and network in a short period of time can handle large amounts of complex data, to improve work efficiency and quality of cost control and management has a positive significance, to ensure the capital cost minimum under the premise of guarantee engineering quality, safety and progress.

\section{Improve the Project Cost Management Model}

Establishing a sound investment control system, and establishing construction supervision and management mechanism, the pursuit of effective control of investment projects, in accordance with the provisions on the supervision and implementation details, and improving relevant systems, implement the responsibility to establish a sound investment control system from the project management mechanism. At the same time preparing monthly engineering, reviewing progress payment and avoiding runaway investment. Reviewing progress payment, the amount of the project that be determined by the supervising party, according to the contract agreed valuation basis, the material unit price and the cost of a fixed price to pay the corresponding project progress.

\section{Perfect Contract Management Work}

The signing of the contract is carried out before the building engineering construction, the formulation and signing of the contract must be strictly in accordance with the requirements of the relevant rules and regulations. Generally contract must include the project period, the price and the manner of payment, etc., so when signing a contract need to scrutiny of these projects, and restrain the unbalanced quotation, reasonable control of price and contract price, detail description of the materials, equipment, quality, technology, labor costs and other requirements in the contract. At the same time, it is necessary to have a certain predictability of the contract claims and fully consider the possibility of rising to the claim controversial point, so as to avoid the occurrence of claims.

\section{SUMMARY}

In summary, the project cost control is an important part for cost management. Engineering cost control based on data mining is that, based on screening and analyzing a large number of complex data from internal and external, at all stages ofthe project, timely adjust the bias, rationally use the human, material and financial resources. Strengthening the enterprise project cost control, which can effectively improves the economic efficiency of enterprises, and promotes long-term development. At present, there are still many questions about their cost control in construction project cost, especially the high investment companies such as grid enterprises. It is necessary to adopt measures to reasonably control costs and maximize efficiency. 


\section{ACKNOWLEDGEMENT}

Yan Peng(1972-), female, research direction is technical and economic disciplines; Yang Ding (1986), male, on-the-job postgraduate student; Yuanmei Yu(1991-), female.

\section{REFERENCES}

[1] PuJia. Project cost control and analysis [J]. Project quality management and control, 2016.03:182-183.

[2] Guohua Song. The importance of the cost control of construction cost and electrical equipment installation in cost control in the substation engineering construction process $[\mathrm{J}]$. Management and managers, 2015(27):331-333.

[3] Jan Emblemsavg.Life-cyele Costing: Using Activity-based Costing and Monte Carlo Methods to Manage Future Costs and Risks [M], JohnWiley\&Sons.2003:51-92.

[4] Dan M. Frangopol Hitoshi Furuta. Analysis and Design of Civil Infrastructure Systems [M], American Society of Civil Engineers, 2001:96.

[5] ZhiyingXu.Cost control researchbased on total life cycle theory [D]. Chengdu University of Technology.2008.

[6] Yinghua Zhao. Discussion on the various stages of civil engineering construction cost control [J]. Value Engineering, 2013(06):58-62.

[7] JunhongGeng. Try to discuss the budget estimate and cost control in the Project Cost [J]. China Building Materials Science \& Technology, 2014(2):115-116.

[8] LifengTian, XinlunGao. Project Cost Study Based on Economy Cost Control [J]. China Building Materials Science \& Technology, 2015(3):98-100.

[9] Guohua Li. Problems and Countermeasures in grid project cost [J]. Global Market InformationGuide, 2014:39-40. 